\title{
Biomarkers of toluene exposure in rats: mercapturic acids vs. traditional indicators (urinary hippuric acid and o-cresol and blood toluene)
}

Frédéric Cosnier*, Benoît Cossec, Manuella Burgart, Hervé Nunge, Céline Brochard, Marie-Josèphe Décret, Aurélie Rémy

\author{
*To whom correspondence should be addressed: \\ Institut National de Recherche et de Sécurité (INRS) \\ Rue du Morvan CS 60027 \\ Vandoeuvre, 54519 cedex, France \\ Tel: + $33(0) 383502032$ \\ Fax: +33 (0)383502096 \\ frederic.cosnier@inrs.fr
}

\section{Abstract}

1. Toluene (TOL) is a neurotoxic, ototoxic and reprotoxic solvent which is metabolized via the glutathione pathway, producing benzylmercapturic, o-, m- and p-toluylmercapturic acids (MAs). These metabolites could be useful as biomarkers of TOL exposure.

2. The aims of this work were 1) to provide data on MAs excretion in rat urine following TOL exposure by inhalation, 2) to compare them to data from traditional TOL biomarkers i.e., TOL in blood (Tol-B), and urinary hippuric acid (HA) and o-cresol (oCre), and 3) to establish the relationships between these different indicators and the airborne TOL concentration (Tol-A).

3. Sprague-Dawley rats were exposed to a range of TOL concentrations. Blood and urine were collected and analyzed to determine biomarker levels.

4. Levels of the four MAs correlate strongly with Tol-A (comparable to the correlation with Tol-B).

5. MAs are thus clearly superior to oCre and HA as potential markers of exposure to TOL.

Keywords: toluene, mercapturic acids, ortho-cresol, hippuric acid, inhalation, biomonitoring 


\section{Introduction}

In industry, toluene (TOL) is the most commonly used monocyclic aromatic hydrocarbon. It is mainly used as a solvent and is a component in paints, varnishes, printing inks, adhesives, waxes, etc. It is also used as feedstock for the manufacture of multiple products (ATSDR, 2000).

A number of occupational studies have examined the effects of TOL exposure via inhalation. The most sensitive effects observed in humans following inhalation exposure are neurological, including altered colour vision, dizziness, fatigue, headache, and decreased performance in neurobehavioral tests (USEPA, 2005). TOL is also considered ototoxic and can exacerbate the effects of noise in humans (Hoet and Lison, 2008). TOL has been classed by the European Union as a reprotoxic product, it may cause miscarriages during early pregnancy at exposure levels below $100 \mathrm{ppm}$ (ATSDR, 2000, Hannigan and Bowen, 2010). These two effects combined with the regular observation of visual impairments led the American Conference of Governmental Industrial Hygienists (ACGIH) to recommend $20 \mathrm{ppm}$ as the time-weighted average threshold limit value (TWA-TLV). In France, the permissible upper limit value for TOL exposure over $8 \mathrm{~h}$ is $50 \mathrm{ppm}$ (100 ppm for $15 \mathrm{~min})$.

Biological monitoring of occupational exposure to this solvent is based on TOL metabolism (Figure 1). Various biomarkers have been used or proposed to assess this exposure. The major metabolic pathway (83-94\% of urinary metabolites) produces hippuric acid (HA), which has been the marker of choice for years. Many studies have compared HA excretion to o-cresol (oCre) excretion. oCre is excreted in urine as a sulfate or glucuronide as a result of ring hydroxylation of TOL (Apostoli et al., 1982, Dossing et al., 1983, Hasegawa et al., 1983, De Rosa et al., 1987, Angerer and Kramer, 1997, Truchon et al., 1999). These two markers correlate with the airborne TOL concentration (Tol-A). However, in humans, HA is only valid for relatively intense TOL exposure. When TOL-A is low (e.g., at less than $10 \mathrm{ppm}$ ) this marker only correlates poorly with exposure levels. At high exposure levels, oCre performs similarly to HA as a marker. In contrast, oCre appears to perform better than HA at lower TOL concentrations (below 50 ppm) (Truchon et al., 1999). However, due to background levels, oCre cannot be used as an indicator of very low concentrations, close to 2 ppm (Inoue et al., 2008). 
As efforts are being made to reduce TOL exposure levels, more specific markers are needed for biological monitoring. At the moment, to assess low TOL exposure levels (e.g., 10 ppm or less), unmetabolized TOL in blood (Tol-B) (Mizunuma et al., 1994) or in urine (Tol-U) seem to be better indicators than urinary HA or oCre (Kawai et al., 1996, Fustinoni et al., 2007, Ukai et al., 2007, Ducos et al., 2008, Ikeda et al., 2008, Inoue et al., 2008, Kawai et al., 2008). Because of the invasive nature of blood sampling, Tol-U is preferred (Fustinoni et al., 2000). However, care must be taken to avoid contaminations or possible losses due to evaporation (Ikeda, 1999, Ducos et al., 2008). Unmetabolized TOL can also be measured in saliva (Ferrari et al., 2008) or in exhaled air (Apostoli et al., 1982, Pierce et al., 1998, Pierce et al., 2002, Ghittori et al., 2004), but fewer studies have been published.

Other urinary TOL metabolites are known and can be measured. Benzyl alcohol is one such compound (Kawai et al., 2007) which was proposed as an exposure marker, but it was shown to be of limited value in estimating TOL exposure levels (Ukai et al., 2007). Finally, a whole family of metabolites which may be useful biomarkers of exposure (BE) has not been extensively investigated: the mercapturic acids (MAs). Recent studies confirm that MAs are useful as BE for electrophilic chemicals (Maestri et al., 1997, Haufroid and Lison, 2005). TOL produces two MAs, S-benzylmercapturic acid (BMA) (Takahashi et al., 1994, Maestri et al., 1997, Inoue et al., 2002) and S-p-toluylmercapturic acid (pTMA) (Angerer et al., 1998) through side-chain oxidation and ring oxidation, respectively. Thus, BMA is thought to be formed via conjugation of benzyl alcohol with glutathione (catalyzed by glutathione-S-transferases), followed by the concerted catalytic action of $\gamma$-glutamyltranspeptidase, releasing glutamic acid, amino peptidase $\mathrm{M}$, releasing glycine, and $\mathrm{N}$-acetyltransferase, which adds an acetyl group. pTMA is thought to be produced from a 3,4-TOL epoxide intermediate by a similar series of reactions. No study has compared pTMA to known BE. BMA has been compared with other markers, and seems to be a better indicator than HA or oCre (Inoue et al., 2002, Inoue et al., 2004). However, at low concentrations $(<15 \mathrm{ppm})$ it does not correlate as well as Tol-U with Tol-A (Ikeda et al., 2008, Inoue et al., 2008, Lovreglio et al., 2010). These poorer correlations may partly be explained by the analytical techniques employed which, until very recently, were probably not sensitive enough to quantify the BMA concentrations induced by 
environmental exposure. In corroboration of this, Aylward et al. (Aylward et al., 2008) estimate that insufficient data on quantitative relationships between these metabolites and TOL exposure, or blood levels, are currently available.

Recently, we developed a new sensitive gas chromatography - tandem mass spectrometry (GC-MS/MS) method which allows simultaneous determination of the two known TOL-related MAs, BMA and pTMA, and two other ring oxidation TOL mercapturic acids, $o$ - and $m$-toluylmercapturic acids (oTMA and mTMA) in urine. These other metabolites were detected in rat urine for the first time using this technique (Cosnier et al., 2012).

The purpose of the present study was to provide data on the excretion of MAs in rat urine following exposure to TOL by inhalation. TOL metabolism is similar in humans and rats, making it possible to use animal experiments with single, stable and controlled exposures. These conditions clearly cannot be found in real occupational situations. To determine whether MAs are good BE candidates, it will be examined how MAs correlate with Tol-A and how they compare with Tol-B and the TOL biomarkers currently used: HA and oCre. 


\section{Materials and methods}

\section{$\underline{\text { Animals }}$}

Male Sprague-Dawley rats were purchased from Charles Rivers Laboratories (Saint Germain sur l'Arbresle, France) and weighed between 200 and $220 \mathrm{~g}$ on arrival at the animal facility. Before exposure, all animals were acclimatized for at least 2 weeks with a 12:12 $\mathrm{h}$ day/night cycle in polycarbonate cages containing irradiated corn cob LabCob12 bedding (DIETEX, Saint Gratien, France) and covered with spun-bonded polyester cage filter. A04 irradiated food (SAFE, Augy, France) and tap water were available ad libitum. The temperature in the animal quarters was $22 \pm 2{ }^{\circ} \mathrm{C}$ and the relative humidity was $55 \pm 10 \%$. Animal experiments were performed according to ethical regulations of animal experimentation (European Directive 2010/63/EU) in a French Ministry of Agriculture-accredited animal facility (Accreditation $\left.\mathrm{N}^{\circ} \mathrm{C} 54-547-10\right)$.

\section{$\underline{\text { TOL exposure }}$}

Groups of eight rats (one concentration per group) were exposed to TOL vapours using a whole-body exposure system. Animals were exposed to 2, 5, 20, 50, 200 and $500 \mathrm{ppm}$ for 6 hours/day (from 09:00 am to 03:00 pm), 5 days/week for one week in $200 \mathrm{~L}$ glass/stainless steel inhalation chambers. During the 6-hour exposure period, the rats did not have access to food or water. In the inhalation chambers, the animals were separated from each other by small wire mesh fences. The inhalation chambers are designed to sustain a dynamic and adjustable airflow $\left(5-6 \mathrm{~m}^{3} \cdot \mathrm{h}^{-1}\right)$, they were maintained at a negative pressure of no more than $5 \mathrm{~mm}_{\mathrm{H} 2 \mathrm{O}}$ to prevent any leakage of the test compound. Air entering the chamber was filtered and conditioned at a temperature of $22 \pm 1{ }^{\circ} \mathrm{C}$ and a humidity of $55 \pm 10 \%$. TOL vapours were generated using a thermoregulated glass streamer. The TOL, delivered by a pump, was instantaneously vaporized upon contact with the heated surface and carried forward with the help of additional airflow through the streamer, into the main air inlet pipe of the exposure chambers. Unexposed rats (controls) were maintained in similar chambers, but exposed to clean air.

Exposure levels were measured three times during the 6h-exposure period (at 10:00 am, 12:00 pm and 2:00 pm) and by collecting samples of the chamber's atmosphere using glass tubes packed with 
activated charcoal 18-35 mesh (VWR International S.A.S, Fontenay-sous-Bois, France). TOL was desorbed from the activated charcoal with carbon disulfide. Styrene was added as an internal standard and samples were analyzed on a Varian CP-3800 gas chromatograph equipped with a flame ionization detector. TOL samples were assayed on a $30 \mathrm{~m}$ x $0.53 \mathrm{~mm}(1.5 \mu \mathrm{m}$ film thickness $)$ CP-Sil 5 column (Varian), using helium as the carrier gas at a constant flow of $10 \mathrm{~mL} / \mathrm{min}$. The column temperature program was: $70{ }^{\circ} \mathrm{C}$ for $1 \mathrm{~min}$ then increased to $200{ }^{\circ} \mathrm{C}$ at a rate of $10{ }^{\circ} \mathrm{C} / \mathrm{min}$. The temperature was held at $200{ }^{\circ} \mathrm{C}$ for $1 \mathrm{~min}$. The injector (Flash 1061) and detector were maintained at $240{ }^{\circ} \mathrm{C}$ and 250 ${ }^{\circ} \mathrm{C}$, respectively. These analyses allowed daily calibrations to be performed.

During exposure, a second GC (Perkin Elmer Clarus 500) equipped with a flame ionization detector and an automatic gas sampling valve was also used to perform online concentration measurements every minute to follow the stability of vapour generation throughout exposure.

\section{$\underline{\text { Blood sample collection }}$}

The blood TOL concentration was measured after the first and fifth days of exposure. The rats' tail tip was first warmed in water at $39{ }^{\circ} \mathrm{C}$ before sectioning with a razor blade to collect blood $(\sim 0.8 \mathrm{~mL})$ in 2-mL heparinised screw top vials, with silicone/PTFE screw caps. Collection was performed under anaesthesia with isoflurane gas. For this, a vaporizer, Isotec 4 (Ohmeda), and a generator, $\mathrm{O}_{2}$ Millennium 5 Concentrator (Respironics), were used. Anaesthesia was induced with 4\% isoflurane and then maintained at $2 \%$ during sampling. The collection procedure was completed within 5 min. Blood samples were frozen at $-20{ }^{\circ} \mathrm{C}$ until analysis. Under these conditions, the blood TOL concentration remains unchanged for at least 4 months. For analysis, blood samples were extracted with $0.5 \mathrm{~mL} \mathrm{CS}_{2}$ containing p-xylene as an internal standard. After 10 min shaking, the samples were centrifuged at $1250 \mathrm{rpm}$ for $10 \mathrm{~min}$ at $4{ }^{\circ} \mathrm{C}$. The lower $\mathrm{CS}_{2}$ layer contained the TOL, $0.3 \mathrm{~mL}$ of this layer was transferred to a vial with a glass insert. The sample $(1 \mu \mathrm{L})(2 \mu L$ for animals exposed to 2 ppm) was analyzed using the chromatographic conditions described for atmospheric monitoring. In these conditions, the recoveries for TOL and p-xylene were equal to $98 \pm 4 \%$ and the TOL limit of detection (LOD) was $0.007 \mu \mathrm{g} / \mathrm{g}$ of blood $(\sim 0.004 \mu \mathrm{g} / \mathrm{g}$ for the $2 \mu \mathrm{L}$ injection). 


\section{$\underline{\text { Urine collection }}$}

Following the first and fifth day of exposure, and after blood collection, animals were placed in individual metabolic-type stainless steel cages with free access to food and water from 3:00 pm to 9:00 am the following day. During this $18 \mathrm{~h}$-period, their urines were collected and refrigerated by a cooling system attached to the collection tubes. Urine samples were frozen immediately after collection and stored at $-20{ }^{\circ} \mathrm{C}$. They were thawed just before analysis.

To account for variability in urine volumes, metabolite concentrations were expressed relative to creatinine concentration. Creatinine concentrations in urine were determined by the Jaffé method using a creatinine test kit (Randox Laboratories, France).

\section{Hippuric acid (HA) analysis}

HA concentrations were determined as previously described (Campo et al., 2006). Briefly, urine and standard samples were first cleaned using a solid-phase extraction (SPE) cartridge. Then, each sample was centrifuged $\left(1750 \times \mathrm{g}\right.$ ) for $10 \mathrm{~min}$ at $10^{\circ} \mathrm{C}$. A $60 \mu \mathrm{L}$ aliquot of cleared, centrifuged sample (urine or standard) was applied to an activated strong anion exchange column (BondElut cartridge; Varian). Then, an $800 \mu \mathrm{L}$ aliquot of the internal standard (IS), 3-methyl hippuric acid (MHA; Aldrich 98\%; 1 $\mathrm{g} / \mathrm{L})$ was added. After rinsing the column with water, HA and MHA were eluted using $3 \mathrm{~mL}$ of methanol/acetic acid (MeOH/AcOH: 9/1; v/v) mixture. The eluate was dried at $70{ }^{\circ} \mathrm{C}$ for 40 min and reconstituted in an aliquot of HPLC buffer ( $4 \mathrm{~mL}$; water/methanol/AcOH: 60/40/1; v/v/v). Chromatographic separation was performed at a flow rate of $1 \mathrm{~mL} / \mathrm{min}$ in a Lichrospher $\mathrm{C} 8$ column (length 250, i.d. $4.6 \mathrm{~mm}, 5 \mu \mathrm{m}$ ). The Shimadzu SPD 10 AVp UV detector was set at $254 \mathrm{~nm}$. Recoveries were $98 \pm 2 \%$ for HA and MHA, reproducibility was $\leq 2 \%$ and the LOD was $4 \mathrm{mg} / \mathrm{L}$ in water.

\section{Cresols analysis}

The concentrations of oCre and its two isomers, the $m$-cresol (mCre) and the $p$-cresol (pCre), in rat urine were measured according to (Truchon et al., 1996) with slight modifications. Briefly, $50 \mu \mathrm{L}$ of sulphuric acid (95\%) was added to a $0.5 \mathrm{~mL}$ aliquot of urine to hydrolyze cresol conjugates. Then, 50 
$\mu \mathrm{L}$ of a $4 \mathrm{mg} / \mathrm{L}$ aqueous solution of 2-ethylphenol (oEtPhOH) (Aldrich, 99\%) was added as internal standard. After shaking, the mixture was heated at $95{ }^{\circ} \mathrm{C}$ for 2 hours, and allowed to cool to room temperature. Excess acidity was neutralized with $1 \mathrm{~mL}$ of $\mathrm{Na}_{2} \mathrm{CO}_{3}(100 \mathrm{~g} / \mathrm{L})$, and cresols and standards were extracted with $500 \mu \mathrm{L}$ of diisopropyl ether. The mixture was shaken for $15 \mathrm{~s}$. After separation of the two layers by centrifugation at $1250 \mathrm{rpm}$ at $4{ }^{\circ} \mathrm{C}$ for $10 \mathrm{~min}$, approximately $300 \mu \mathrm{L}$ of the upper organic layer was collected and analyzed. Under these conditions, recoveries were $80 \pm 7 \%$ for oCre, $88 \pm 8 \%$ for oEtPhOH, $79 \pm 10 \%$ for mCre and $74 \pm 7 \%$ for $\mathrm{pCre}$

Cresols were separated by gas chromatography (GC Shimadzu 2010+) on a Supelcowax-10 column (length $60 \mathrm{~m}$, i.d. $0.25 \mathrm{~mm}$, film thickness $0.25 \mu \mathrm{m}$ ) with helium as carrier gas at a constant velocity of $40 \mathrm{~cm} / \mathrm{s}$. The injector (splitless mode for $0.5 \mathrm{~min}$ ) temperature was set at $250{ }^{\circ} \mathrm{C}$, and that of the detector at $270{ }^{\circ} \mathrm{C}$.

The oven temperature program was as follows: $60{ }^{\circ} \mathrm{C}(0.5 \mathrm{~min})$ then increased to $180{ }^{\circ} \mathrm{C}$ at a rate of $30{ }^{\circ} \mathrm{C} / \mathrm{min}$, further increased to $225^{\circ} \mathrm{C}$ at $10{ }^{\circ} \mathrm{C} / \mathrm{min}$ (held $3 \mathrm{~min}$ ), and, finally increased to $250{ }^{\circ} \mathrm{C}$ at $10{ }^{\circ} \mathrm{C} / \mathrm{min}$ (held $4.5 \mathrm{~min}$ ). The total run time was $19 \mathrm{~min}$.

Under these conditions, the retention times were: $10.39 \mathrm{~min}$ for oCre, 10.98 for oEtPhOH, 11.19 for pCre, and 11.29 for mCre. The oCre chromatographic peak was well resolved and could be quantified; the peaks for pCre and mCre were not completely separated, but nevertheless allowed quantification.

Calibration ranges were prepared for each cresol: 0.1 to $15 \mathrm{mg} / \mathrm{L}$ for oCre, 0.01 to $1.5 \mathrm{mg} / \mathrm{L}$ for mCre, and 0.3 to $45 \mathrm{mg} / \mathrm{L}$ for pCre. Because pCre is naturally present in blank urine, these standard samples were prepared in water by adding aliquots of a $100 \mathrm{mg} / \mathrm{L}$ stock solution of the appropriate cresol dissolved in methanol. For these assays, LODs were $30 \mu \mathrm{g} / \mathrm{L}$ for oCre, $50 \mu \mathrm{g} / \mathrm{L}$ for mCre, and 300 $\mu \mathrm{g} / \mathrm{L}$ for $\mathrm{pCre}$.

\section{Mercapturic acid analysis}

The procedure for analyzing MAs has been exhaustively described (Cosnier et al., 2012). Briefly, frozen urine samples were allowed to equilibrate to room temperature. Samples were shaken, and $200-\mu \mathrm{L}$ aliquots were then transferred into 5 -mL glass tubes; $60 \mu \mathrm{L}$ of $1 \mathrm{M} \mathrm{HCl}$ and $50 \mu \mathrm{L}$ of 20 
$\mathrm{mg} / \mathrm{L}$ IS (IS $=3,5$-dimethylbenzylmercapturic acid $=3,5$-dMBMA) were added, and the total volume was made up to $510 \mu \mathrm{L}$ with distilled water. The mixtures were then extracted three times with $1 \mathrm{~mL}$ chloroform $\left(\mathrm{CHCl}_{3}\right)$. The three $\mathrm{CHCl}_{3}$ layers were collected in 5-mL hermetically closed PTFE-lined screw cap glass tubes and evaporated to dryness at $60^{\circ} \mathrm{C}$. After adding $60 \mu \mathrm{L}$ of $1 \mathrm{M} \mathrm{HCl-isopropanol}$ and $300 \mu \mathrm{L}$ of TOL to the residue, MAs were esterified in a domestic microwave oven (FT331, Whirlpool) at $750 \mathrm{~W}$ for $4 \mathrm{~min}$. After heating, remaining acidity was neutralized with $60 \mu \mathrm{L}$ of $\mathrm{Na}_{2} \mathrm{CO}_{3}$. The mixture was then vortexed and centrifuged ( $2500 \mathrm{rpm}$ for $15 \mathrm{~min}$ ) before collecting the organic layer. Samples were then analyzed by GC-MS/MS. Recovery yields for the complete procedure are close to $100 \%$ for all compounds for urine samples spiked at 0.1 and $1.0 \mathrm{mg} / \mathrm{L}$. A $10 \%$ to $15 \%$ decrease in yield was observed at higher concentrations $(10 \mathrm{mg} / \mathrm{L})$.

Gas chromatography (GC) was performed on a 450-GC system (Bruker, Wissembourg, France) equipped with a CP-8400 autosampler (Bruker). Compounds were separated on an Rxi-5Sil MS capillary column with integra-guard (30 m length $\times 0.25 \mathrm{~mm}$ I.D. $\times 0.25 \mu \mathrm{m}$ film thickness), using helium as the carrier gas at a constant flow of $1.3 \mathrm{~mL} / \mathrm{min}$. The sample $(1 \mu \mathrm{L})$ was injected in splitless mode (injector type 1177) at an injection temperature of $250{ }^{\circ} \mathrm{C}$, the split delay and split ratio were set at $0.5 \mathrm{~min}$ and $1 / 50$, respectively. The oven temperature was held at $75^{\circ} \mathrm{C}$ for $0.5 \mathrm{~min}$, then increased to $195{ }^{\circ} \mathrm{C}$ at a rate of $20{ }^{\circ} \mathrm{C} / \mathrm{min}$ and held at $195^{\circ} \mathrm{C}$ for $10 \mathrm{~min}$, it was then increased to $270{ }^{\circ} \mathrm{C}$ at 10 ${ }^{\circ} \mathrm{C} / \mathrm{min}$ and finally held at $270{ }^{\circ} \mathrm{C}$ for $1 \mathrm{~min}$ (total time: $25 \mathrm{~min}$ ). The transfer line was maintained at $270{ }^{\circ} \mathrm{C}$ throughout.

GC-MS/MS analyses were acquired using a 320 triple quadrupole mass spectrometer (Bruker, Wissembourg, France) in electronic impact (EI) mode. Ion source temperature was set at $200{ }^{\circ} \mathrm{C}$ and ionization energy at $70 \mathrm{eV}$. Selected reaction monitoring (SRM) data were acquired using argon $99.9999 \%$ (Air Liquide) as collision gas at a pressure of 2.0 mtorr in the collision cell. The source was flushed with helium gas for the first 14 min of injection. Two SRM ion transitions per compound were chosen based on selectivity and abundance. To maximize signal-to-noise ratio in matrix extracts, one of these transitions was used as quantifier and the second as qualifier. Dwell time was fixed at 0.1 $\mathrm{s}$ for all transitions.

With this method, LOD was 2.8 for oTMA, 3.6 for mTMA, 4.6 for pTMA, and $5.5 \mu \mathrm{g} / \mathrm{L}$ for BMA. 


\section{Statistical analysis}

All statistical analyses were performed using Stata 12.1 (Stata College station, Texas, USA). Each condition and indicator was analyzed using paired Student's t-test followed by Bonferroni correction to determine overall significant differences at the $95 \%$ confidence interval between days 1 and 5 of collection.

For HA, the endogenous toluene indicator, an ANOVA test was followed by a Bonferroni test to compare the mean HA concentrations in urine for controls and exposed rats. In occupational health studies, and where experimental data are not normally distributed, a ln-transformation is generally used to normalize data and homogenize variances. This was used here. However, due to the low number of values $(\mathrm{n}=8)$, to facilitate interpretation and comparison with other investigations, only the means and standard errors (rather than the geometric mean and standard deviation) are reported for all indicators (Table 1). In addition to calculating simple summary statistics, toluene exposure indicators were analyzed using linear mixed effect models on the ln-transformed scale. A fixed effect (interesting in itself) was used to model the effect of atmospheric toluene (on a log scale). A random effect (interesting in the underlying population) was used to model systematic differences between rats, these appear with repeated measurements for the same animal.

The models can be represented as follows:

$$
\ln \left(Y_{\mathrm{ij}}\right)=\alpha+\beta \ln \left(\mathrm{X}_{\mathrm{ij}}\right)+\xi_{\mathrm{j}}+\varepsilon_{\mathrm{ij}}
$$

where $Y_{i j}$ is the $i^{\text {th }}$ measurement of an exposure indicator for the $j^{\text {th }}$ rat, $\alpha$ is the intercept of the model (overall mean of the model on a $\log$ scale), and $\beta$ is the fixed effect coefficient (slope) for the ln-transformed atmospheric toluene concentration. The random effect $\xi_{\mathrm{j}}$, and residual error $\varepsilon_{\mathrm{ij}}$ (withinindividual error) were assumed to be normally distributed with a mean of zero and standard deviation of $\psi$ and $\theta$, respectively.

For HA, the endogenous toluene indicator, we used the ln-transformed atmospheric toluene concentration plus one as a fixed effect. This allowed inclusion of the HA values for animals not exposed to toluene.

The models were validated by analyzing the residuals from the models. 


\section{Results}

The summary statistics (means and standard deviations) for all inhalation exposures are presented for the eight indicators (Tol-B, HA, oCre, mCre, BMA, oTMA, mTMA and pTMA) following the first and fifth days of exposure (Table 1).

\section{$\underline{\text { Day-effect }}$}

Statistical analysis of the atmospheric concentrations revealed no difference between day 1 and day 5 . The day-effect was also tested using paired t-test and Bonferroni correction for each indicator, and each concentration. No overall statistical difference between day 1 and 5 was found for any indicator.

\section{Hippuric acid analysis}

As HA is an endogenous product, all the urine samples analyzed, including controls, contained a significant amount. Except for TOL20, mean urinary concentrations of control animals were similar. All experiments combined, the mean level for controls is equal to $0.52( \pm 0.15)$. A statistically significant difference between exposed and controls was only observed for rats exposed to $50 \mathrm{ppm}$ toluene (on day 5 only) or higher. Below this concentration, the amount of HA present in urine cannot be clearly attributed to toluene exposure.

Correction for creatinine is controversial since it does not always improve the correlation between the external doses and urinary exposure marker levels (Inoue et al., 2008, Kawai et al., 2010). Nevertheless, its influence on the HA concentration was investigated. In this case, this correction does not reduce the significance level. This is essentially due to the homogeneity of creatinine levels: mean concentration $=0.42 \pm 0.09(\mathrm{n}=144)$. For this reason, creatinine-corrected values are not reported in this paper.

The limit HA values recommend in humans after exposure to $50 \mathrm{ppm}$ TOL-A by the French and Swiss authorities are $2.5 \mathrm{~g} / \mathrm{g}$ creatinine (end of shift) and $2 \mathrm{~g} / \mathrm{g}$ creatinine (end of shift after several shifts), respectively. These values are slightly higher than the results reported here: around $0.73 \mathrm{~g} / \mathrm{L}$ $(1.74 \mathrm{~g} / \mathrm{g}$ creatinine) 


\section{Cresols analysis}

No results for pCre are reported due to the high baseline level in controls (resulting from the degradation of phenylalanine and phenol compounds in vegetables) and the heterogeneity of responses in treated animals, as previously observed (Inoue et al., 1984). For oCre and mCre, the concentrations in controls were systematically lower than the LOD for the analytical method. With mCre, exposure to at least $20 \mathrm{ppm}$ is necessary to exceed the LOD $(50 \mu \mathrm{g} / \mathrm{L})$. This complicates its use as an indicator of toluene exposure. Considering all the measurements obtained for Tol-A > 20 ppm, the average ratio between oCre and $\mathrm{mCre}$ is $9.7 \pm 2.0$.

The oCre concentration excreted in urine after exposure to $20 \mathrm{ppm}$ and $50 \mathrm{ppm}$ Tol-A (US and EU TLV) was approximately 0.4 and $1.2 \mathrm{mg} / \mathrm{L}$, respectively. These values are similar to those recommended for humans by the ACGIH (Biological Exposure Indice: $0.3 \mathrm{mg} / \mathrm{g}$ creatinine, end of shift after several shift) or by the German regulations (Biologischer Arbeitsstoff-Toleranz-Wert: 600 $\mu \mathrm{g} / \mathrm{L}$, end of shift).

\section{Mercapturic acids analysis}

The amounts of the different MA isomers are within similar ranges to the cresols (a few mg/L). As shown in figure 2A, the distribution of MAs produced by ring- or side-chain-oxidation depends on exposure level. At low concentrations, ring oxidation MAs ( 3 compounds) predominate $(\approx 60 \%$ of the total amount excreted). In contrast, at high exposure levels, BMA is preponderant (55\%). pTMA is the major TMA isomer (Figure 2B). Its relative abundance tends to increase with Tol-A. On average, the ratio of oTMA, mTMA and pTMA was approximately 2/1/6.

\section{$\underline{\text { Regression of biomarker levels with airborne toluene }}$}

The relationship between the different indicators (in blood and urine) and atmospheric toluene are reported using a logarithm scale (Figure 3). These relationships were independently modelled using linear mixed-effect models. The fitted model, with prediction limits, is also presented in Figure 3. The regression equations calculated for each model, and some related estimates (needed to compare the 
different models) are presented in Table $2 . \mathrm{R}^{2}$ is the percentage of variance explained by a fixed effect. $\rho$ (rat) is the intra-class correlation coefficient (ICC, its value varies between 0 and 1). $\rho$ (rat) can be considered a reliability test as it is the part of variance explained by random effects, after inclusion of the fixed effect in the model.

The linear regression analysis revealed a highly significant relationship between Tol-B and Tol-A, $\mathrm{R}^{2}=0.98$ and $\mathrm{ICC}=0.72$. The corresponding fitted equation between the natural logarithm for both parameters is: $\ln$ Tol-B $=-5.37( \pm 0.09)+1.29( \pm 0.02) \times \ln$ Tol-A. This equation is similar to that previously obtained from inhalation exposure of Long-Evans rats to 50, 100, 500 and $1000 \mathrm{ppm}$ toluene for 3 hours (Benignus et al., 1984) (ln Tol-B $=-6.53+1.43 \times \ln$ Tol-A; $\mathrm{R}^{2}=0.98$ ).

The four MAs (BMA, o, m and pTMA) also significantly correlate with Tol-A $\left(\mathrm{R}^{2}=0.96\right)$. This correlation is better than that obtained with oCre $\left(\mathrm{R}^{2}=0.92\right)$. In contrast, correlation was significantly poorer for HA $\left(\mathrm{R}^{2}=0.52\right)$ due to the absence of correlation between HA and Tol-A when Tol-A was $<50 \mathrm{ppm}$.

When Tol-A $\leq 20 \mathrm{ppm}$ (Table 3$)$, Tol-B is still very well correlated with Tol-A $\left(\mathrm{R}^{2}=0.96\right) . \mathrm{R}^{2}$ obtained for MAs range from 0.80 (oTMA) to 0.87 (pTMA) while that found for oCre drops to 0.50 . 


\section{Discussion}

The goal of this study performed in rat exposed to toluene vapours $(2-500 \mathrm{ppm})$ by inhalation was, primarily, to provide data on the urinary concentrations of four MAs derived from side-chain (BMA) and ring oxidation of toluene ( $\mathrm{o}, \mathrm{m}$ and $\mathrm{pTMA})$. These data were compared to those obtained for the commonly used biomarkers, HA, and cresols (especially oCre).

The MAs concentrations detected in rat urine are of similar magnitude to cresol concentrations (a few $\mathrm{mg} / \mathrm{L}$ ) and about 1,000-fold lower than HA levels (measured in $\mathrm{g} / \mathrm{L}$ ). Rats and humans differ by the relative proportion of MAs in the total metabolites excreted. Indeed, occupational studies investigating BMA and pTMA in human urine revealed concentrations in the tens to hundreds of $\mu \mathrm{g} / \mathrm{L}$ range (Maestri et al., 1997, Angerer et al., 1998, Inoue et al., 2002, Inoue et al., 2004, Ukai et al., 2007, Ikeda et al., 2008, Inoue et al., 2008, Kawai et al., 2010, Lovreglio et al., 2010). The BMA to pTMA ratio also appears to differ between humans and rats, it nears 9.5 (median BMA and pTMA equal to 190 and $20 \mu \mathrm{g} / \mathrm{L}$, respectively) for humans (Angerer et al., 1998), compared to between 1.5 and 2 for rats (this study). This suggests that oxidation of the aromatic ring occurs more frequently in rats than in humans, a hypothesis supported by the lower HA / oCre ratio observed in rats. In rat, the ratio BMA / TMA depends also on the concentration. TMAs predominate at low concentrations whereas BMA is preponderant at high exposure levels. This inversion is probably due to the first oxidation step during TOL metabolism; indeed, the formation of arene oxides is either saturated faster or displays slower kinetics than benzyl alcohol formation.

The period and duration of sample collection are essential criteria in this type of study. In human studies, urine samples are generally spot samples taken at the end of a shift. In the protocol used here, all the urine excreted over the 18 -h post exposure period was collected. With this method, elimination kinetics for individual animals have little influence on results. In humans, $65 \%$ of the HA produced is excreted within 4 hours, $80 \%$ after 20 hours, and elimination is complete within 24 hours (Lof et al., 1993). oCre has a biphasic elimination half-life: 3-4 hours and 22 hours (its elimination kinetics vary considerably between individuals). For MAs, the elimination kinetics have yet to be determined. Angerer et al. (Angerer et al., 1998) assume that the half-life of pTMA is similar to that of S- 
phenylmercapturic acid (MA produced from benzene), at about $10 \mathrm{~h}$ in humans. In corroboration of this, data from a pilot animal study (own unpublished results) involving Sprague-Dawley rats exposed for 6 hours to toluene (5-2000 ppm) by inhalation through the nose only - showed that, for all concentrations, $65 \pm 15 \%$ of BMA and $67 \pm 19 \%$ of pTMA excreted over the 24 hours following the start of exposure was excreted during the following 18h-post exposure period. BMA and pTMA amounts were revealed by HPLC/fluorescence, based on a method adapted from Maestri (Maestri et al., 1997, Campo et al., 2006). Contrary to HA and oCre, MAs are thus mainly produced after the exposure. It could be a good thing for the biological monitoring if observations in rat are transposable to human. The best collection period need nevertheless to be determined. Indeed, in this study the target was not to identify the peak of excretion.

The ratios for the different TMA isomers $(2 / 1 / 6: \mathrm{o} / \mathrm{m} / \mathrm{p})$ are similar to those found for the corresponding ring oxidation mercapturic acids of ethylbenzene in rat (1/2/6) (Cossec et al., 2010) and for styrene in mice (2/1/6) (Linhart et al., 2010). Thus, the rates for glutathione's reaction with the 2,3-oxide and 3,4-oxide appear to be the same for all monosubstituted aromatic compounds in rodents. Very recently, Linhart et al. (Linhart et al., 2012) showed that vinylphenylmercapturic acids (VPMA) were present in the urine of hand-lamination workers exposed to styrene. In this case, pVPMA was found to predominate to an extent suggesting a more pronounced regioselectivity for VPMA formation in humans. However, traces of o- and m-VPMA isomers were also detected in urine samples taken at the end of the work-shift for the most exposed operators. We therefore anticipate that oTMA and mTMA will be detectable in urine from TOL-exposed humans, but in smaller amounts than pTMA.

No day-effect was observed for any marker or ratio throughout this study, indicating that no induction phenomenon is present, even at $500 \mathrm{ppm}$. This observation is in agreement with the literature (ATSDR, 2000); in rat, TOL induces hepatic CYP enzymes involved in its own metabolism starting from $1000 \mathrm{ppm}$. All the data collected after day 1 and day 5 of exposure were thus used to construct regression curves comparing Tol-A to the different indicators.

Tol-U and Tol-B are considered by many studies as the indicators of choice for TOL exposure (Fustinoni et al., 2000, Ikeda et al., 2008). The following order of preference is often cited: Tol-U 
Tol-B $>$ oCre $\sim$ BMA $>$ HA. In the present study, the sequence was found to be: Tol-B $\left(\mathrm{R}^{2}=0.98\right)>$ BMA oTMA $\sim$ mTMA $\sim$ pTMA $\left(\mathrm{R}^{2}=0.96\right)>$ oCre $\left(\mathrm{R}^{2}=0.92\right)>$ HA $\left(\mathrm{R}^{2}=0.52\right)($ Table 2$)$. Tol-U was not measured here since the urine collection process did not include all the necessary precautions to avoid TOL loss by evaporation and/or oxidation. Correlation coefficient obtained with Tol-B shows that it closely correlates with TOL-A, even at low concentrations $\left(\mathrm{R}^{2}=0.96\right.$ when Tol-A $\left.\leq 20 \mathrm{ppm}\right)$. Unlike for the urine samples, this excellent correlation cannot be attributed to how blood samples were collected (spot collection, as would be used in an occupational situation). This strong correlation is probably related to the exposure conditions, particularly the stability of the Tol-A concentration over the 6-h exposure period.

When considering the full range of Tol-A $(2-500 \mathrm{ppm}), \mathrm{R}^{2}$ values for the surrogate biomarkers tested are also very high except for HA. This low $\mathrm{R}^{2}$ for HA was expected because it is well known that the presence of these compounds in the urine is not a definitive proof of toluene exposure since it is also produced by metabolism from the normal diet (from benzoates or benzoic acid in fruits, vegetables, and food preservatives) (Lof et al., 1993, Kawai et al., 1996, Pierce et al., 1998). MAs correlations with Tol-A were almost as good as those of Tol-B. At low concentrations (when Tol-A $\leq$ $20 \mathrm{ppm})$, oCre appear to be limited $\left(\mathrm{R}^{2}=0.50\right)$. Previous reports have already made this observation for oCre and BMA (Ikeda et al., 2008, Inoue et al., 2008). In this study, correlation coefficients obtained with MAs decrease at low TOL concentrations (mean $\mathrm{R}^{2}$ equal 0.84 instead of 0.96) but they remain high. This is probably because in this study endogenous levels are too low to be detected. The background levels of MAs in non-exposed populations must be determined as they are key to the potential usefulness of MAs as biomarkers of TOL exposure. Indeed, a biomarker with a low background may be particularly useful for smokers for whom oCre levels may be an unreliable indicator of exposure (Dossing et al., 1983, Truchon et al., 1996, Pierce et al., 1998, Fustinoni et al., 2007, Ukai et al., 2007, Ducos et al., 2008, Inoue et al., 2008). Currently, a doubt remains; only two studies have reported a physiological background level of BMA. Values for this metabolites were in the range $20-40 \mu \mathrm{g} / \mathrm{L}$ for a control group (Angerer et al., 1998), or $6.60 \pm 6.43 \mu \mathrm{g} / \mathrm{g}$ creatinine (Lovreglio et al., 2010). pTMA has never been detected in urine samples from non-exposed control 
groups (Angerer et al., 1998). This study demonstrates that rats excrete more BMA and TMAs than humans, however, neither was detected in rat control urine. These biomarkers are very sensitive; they would detect low toluene exposure. Using our GC-MS/MS analysis method, at just 2 ppm Tol-A, excretion was around 25 and 10 times the LODs for BMA and mTMA, respectively. Therefore, MAs offer clear advantages over traditional urinary biomarkers of TOL exposure. Further studies on TMAs are necessary to increase our knowledge in occupational fields beyond what was revealed by the single study of pTMA (Angerer et al., 1998).

In an occupational environment, workers are exposed to toluene at various levels and for different durations. They are also generally co-exposed to other chemicals such as acetone, ethylacetate, ethylbenzene, methylethylketone, hexane, isopropyl alcohol, xylenes, etc. (Truchon et al., 1999, Ukai

et al., 2007, Inoue et al., 2008). These other compounds may interact with toluene to modify its biotransformation. As a result, the blood TOL burden and excretion of TOL metabolites may be affected. Life-style factors including alcohol consumption and smoking may also affect TOL metabolism. Some of these interactions have already been identified indirectly in field studies, but their real impact on each indicator of TOL exposure has yet to be clarified. This study has paved the way for a broader study devoted to the interactions observed during controlled mixed exposures and their influence on the different biomarkers of toluene exposure, including the MAs.

\section{Declaration of interest}

This work was funded by French National Institute for Research and Safety (INRS) for the prevention of occupational accidents or diseases. The authors report no conflicts of interest.

\section{Acknowledgement}

The authors gratefully acknowledge Philippe Chaumont, Lionel Dussoul, Jean-Claude Gondrexon and Sylvie Michaud for their technical assistance. 


\section{References}

Angerer J, Kramer A. (1997). Occupational chronic exposure to organic solvents. XVI. Ambient and biological monitoring of workers exposed to toluene. Int Arch Occup Environ Health 69:91-6.

Angerer J, Schildbach M, Krämer A. (1998). S-p-toluylmercapturic acid in the urine of workers exposed to toluene: a new biomarker for toluene exposure. Arch Toxicol 72:119-23.

Apostoli P, Brugnone F, Perbellini L, Cocheo V, Bellomo ML, Silvestri R. (1982). Biomonitoring of occupational toluene exposure. Int Arch Occup Environ Health 50:153-68.

ATSDR. Agency for Toxic Substances and Disease Registry. (2000). Toxicological profile for toluene.

Aylward LL, Barton HA, Hays SM. (2008). Biomonitoring Equivalents (BE) dossier for toluene (CAS No. 108-88-3). Regul Toxicol Pharmacol 51:S27-S36.

Benignus VA, Muller KE, Graham JA, Barton CN. (1984). Toluene levels in blood and brain of rats as a function of toluene level in inspired air. Environ Res 33:39-46.

Campo P, Blachère V, Payan JP, Cossec B, Ducos P. (2006). Toluene toxicokinetics and metabolism parameters in the rat and guinea pig. Environ Toxicol Pharmacol 21:27682.

Cosnier F, Brochard C, Burgart M, Cossec B. (2012). Mercapturic acids derived from toluene in rat urine samples: identification and measurement by gas chromatography-tandem mass spectrometry. Anal Bioanal Chem 404:1907-17.

Cossec B, Cosnier F, Burgart M, Nunge H, Grossmann S. (2010). Glutathione pathway in ethylbenzene metabolism: Novel biomarkers of exposure in the rat. Chemosphere 81:1334-41.

De Rosa E, Bartolucci GB, Sigon M, Callegaro R, Perbellini L, Brugnone F. (1987). Hippuric acid and ortho-cresol as biological indicators of occupational exposure to toluene. Am $J$ Ind Med 11:529-37.

Dossing M, Aelum JB, Hansen SH, Lundqvist GR, Andersen NT. (1983). Urinary hippuric acid and orthocresol excretion in man during experimental exposure to toluene. $\mathrm{Br} J$ Ind Med 40:470-3.

Ducos P, Berode M, Francin JM, Arnoux C, Lefevre C. (2008). Biological monitoring of exposure to solvents using the chemical itself in urine: application to toluene. Int Arch Occup Environ Health 81:273-84.

Ferrari M, Negri S, Zadra P, Ghittori S, Imbriani M. (2008). Saliva as an analytical tool to measure occupational exposure to toluene. Int Arch Occup Environ Health 81:1021-8.

Fustinoni S, Buratti M, Giampiccolo R, Brambilla G, Foa V, Colombi A. (2000). Comparison between blood and urinary toluene as biomarkers of exposure to toluene. Int Arch Occup Environ Health 73:389-96.

Fustinoni S, Mercadante R, Campo L, Scibetta L, Valla C, Consonni D, Foa V. (2007). Comparison between urinary o-cresol and toluene as biomarkers of toluene exposure. J Occup Environ Hyg 4:1-9.

Ghittori S, Alessio A, Negri S, Maestri L, Zadra P, Imbriani M. (2004). A field method for sampling toluene in end-exhaled air, as a biomarker of occupational exposure: Correlation with other exposure indices. Ind Health 42:226-34.

Hannigan JH, Bowen SE. (2010). Reproductive Toxicology and Teratology of Abused Toluene. Syst Biol Reprod Med 56:184-200.

Hasegawa K, Shiojima S, Koizumi A, Ikeda M. (1983). Hippuric acid and o-cresol in the urine of workers exposed to toluene. Int Arch Occup Environ Health 52:197-208. 
Haufroid V, Lison D. (2005). Mercapturic acids revisited as biomarkers of exposure to reactive chemicals in occupational toxicology: a minireview. Int Arch Occup Environ Health 78:343-54.

Hoet P, Lison D. (2008). Ototoxicity of toluene and styrene: State of current knowledge. Crit Rev Toxicol 38:127-70.

Ikeda M. (1999). Solvents in urine as exposure markers. Toxicol Lett 108:99-106.

Ikeda M, Ukai H, Kawai T, Inoue O, Maejima Y, Fukui Y, Ohashi F, Okamoto S, Takada S, Sakurai H. (2008). Changes in correlation coefficients of exposure markers as a function of intensity of occupational exposure to toluene. Toxicol Lett 179:148-54.

Inoue O, Kanno E, Kasai K, Ukai H, Okamoto S, Ikeda M. (2004). Benzylmercapturic acid is superior to hippuric acid and o-cresol as a urinary marker of occupational exposure to toluene. Toxicol Lett 147:177-86.

Inoue O, Kanno E, Yusa T, Kakizaki M, Ukai H, Okamoto S, Higashikawa K, Ikeda M. (2002). Urinary benzylmercapturic acid as a marker of occupational exposure to toluene. Int Arch Occup Environ Health 75:341-7.

Inoue O, Kawai T, Ukai H, Maejima Y, Fuku Y, Ohashi F, Okamoto S, Takada S, Sakurai H, Ikeda M. (2008). Limited validity of o-cresol and benzylmercapturic acid in urine as biomarkers of occupational exposure to toluene at low levels. Ind Health 46:318-25.

Inoue O, Seiji K, Ishihara N, Kumai M, Ikeda M. (1984). Increased o- and p-cresol/hippuric acid ratios in the urine of four strains of rat exposed to toluene at thousands-ppm levels. Toxicol Lett 23:249-57.

Kawai T, Eitaki Y, Ukai H, Inoue O, Maeshima Y, Ueda N, Ohashi F, Sakurai H, Ikeda M. (2010). Validation of Urine Density Correction in Cases of Hippuric Acid and Unmetabolized Toluene in Urine of Workers Exposed to Toluene. Ind Health 48:154-63.

Kawai T, Mizunuma K, Okada Y, Horiguchi Si, Ikeda M. (1996). Toluene itself as the best urinary marker of toluene exposure. Int Arch Occup Environ Health 68:289-97.

Kawai T, Ukai H, Inoue O, Maejima Y, Fukui Y, Ohashi F, Okamoto S, Takada S, Sakurai H, Ikeda M. (2008). Evaluation of biomarkers of occupational exposure to toluene at low levels. Int Arch Occup Environ Health 81:253-62.

Kawai T, Yamauchi T, Miyama Y, Sakurai H, Ukai H, Takada S, Ohashi F, Ikeda M. (2007). Benzyl alcohol as a marker of occupational exposure to toluene. Ind Health 45:14350 .

Linhart I, Mraz J, Dabrowska L, Malis M, Krouzelka J, Korinek M. (2012). Vinylphenylmercapturic acids in human urine as biomarkers of styrene ring oxidation. Toxicol Lett 213:260-5.

Linhart I, Mraz J, Scharff J, Krouzelka J, Duskova S, Nohova H, Vodickova L. (2010). New urinary metabolites formed from ring-oxidized metabolic intermediates of styrene. Chem Res Toxicol 23:251-7.

Lof A, Hjelm EW, Colmsjo A, Lundmark BO, Norstrom A, Sato A. (1993). Toxicokinetics of toluene and urinary excretion of hippuric acid after human exposure to ${ }^{2} \mathrm{H}_{8}$-toluene. Br J Ind Med 50:55-9.

Lovreglio P, Barbieri A, Carrieri M, Sabatini L, Fracasso ME, Doria D, Drago I, Basso A, D'Errico MN, Bartolucci GB, Violante FS, Soleo L. (2010). Validity of new biomarkers of internal dose for use in the biological monitoring of occupational and environmental exposure to low concentrations of benzene and toluene. Int Arch Occup Environ Health 83:341-56.

Maestri L, Ghittori S, Imbriani M. (1997). Determination of specific mercapturic acids as an index of exposure to environmental benzene, toluene, and styrene. Ind Health 35:489501. 
Mizunuma K, Horiguchi S, Kawai T, Yasugi T, Ikeda M. (1994). Toluene in blood as a marker of choice for low-level exposure to toluene. Int Arch Occup Environ Health 66:309-15.

Pierce CH, Chen YL, Dills RL, Kalman DA, Morgan MS. (2002). Toluene metabolites as biological indicators of exposure. Toxicol Lett 129:65-76.

Pierce CH, Dills RL, Morgan MS, Vicini P, Kalman DA. (1998). Biological monitoring of controlled toluene exposure. Int Arch Occup Environ Health 71:433-44.

Takahashi S, Kagawa M, Shiwaku K, Matsubara K. (1994). Determination of S-benzyl-Nacetyl-L-cysteine by gas-chromatography mass-spectrometry as a new marker of toluene exposure. J Anal Toxicol 18:78-80.

Truchon G, Tardif R, Brodeur J. (1996). Gas chromatographic determination of urinary ocresol for the monitoring of toluene exposure. J Anal Toxicol 20:309-12.

Truchon G, Tardif R, Brodeur J. (1999). o-cresol: a good indicator of exposure to low levels of toluene. Appl Occup Environ Hyg 14:677-81.

Ukai H, Kawai T, Inoue O, Maejima Y, Fukui Y, Ohashi F, Okamoto S, Takada S, Sakurai H, Ikeda M. (2007). Comparative evaluation of biomarkers of occupational exposure to toluene. Int Arch Occup Environ Health 81:81-93.

USEPA. U.S. Environmental Protection Agency. (2005). Toxicological review of toluene. 


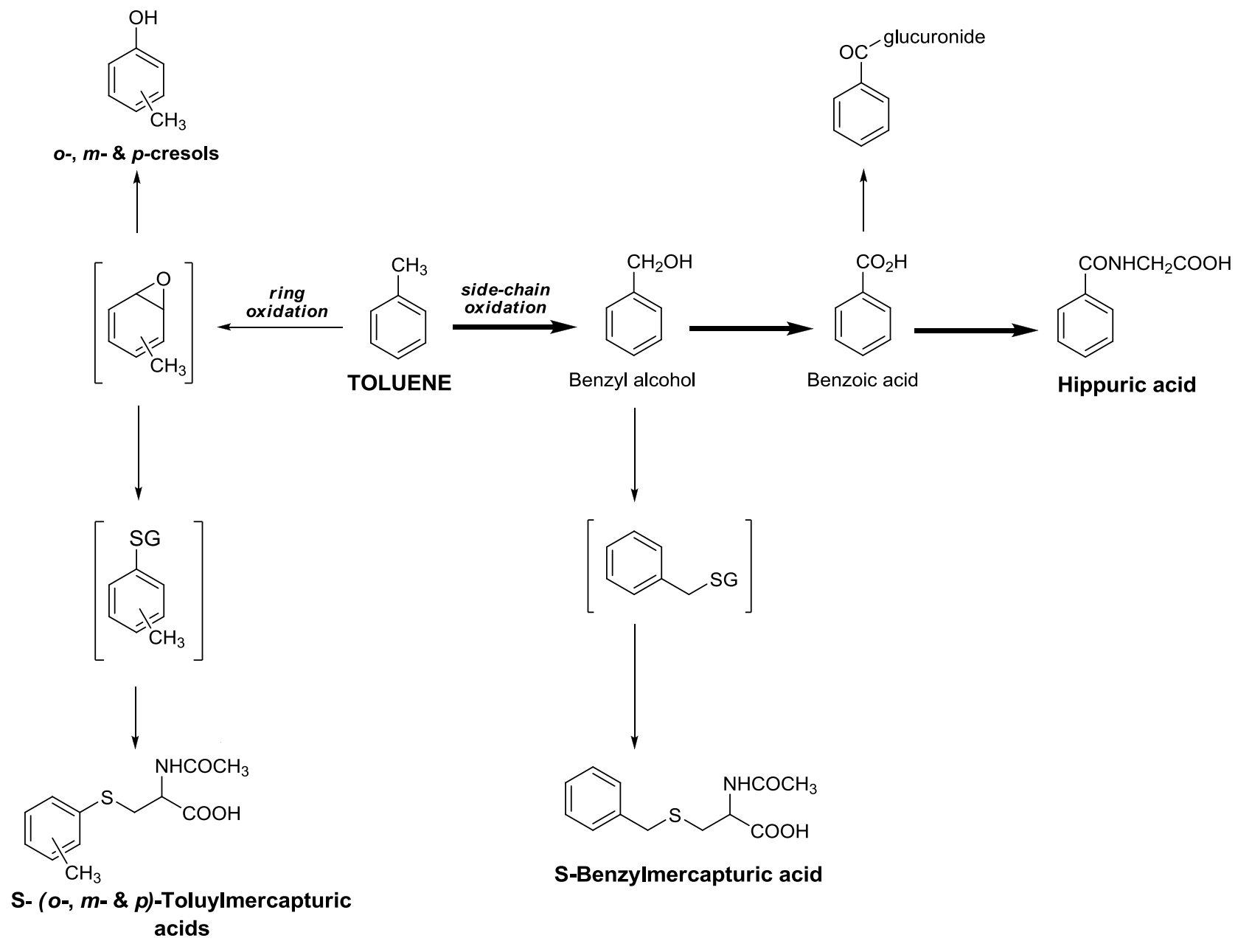

Figure 1. Schematic representation of TOL metabolism in rat and human 
A

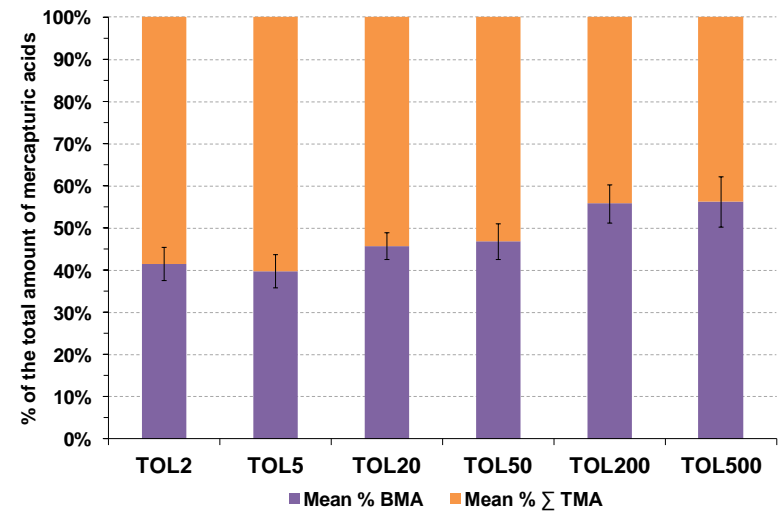

B

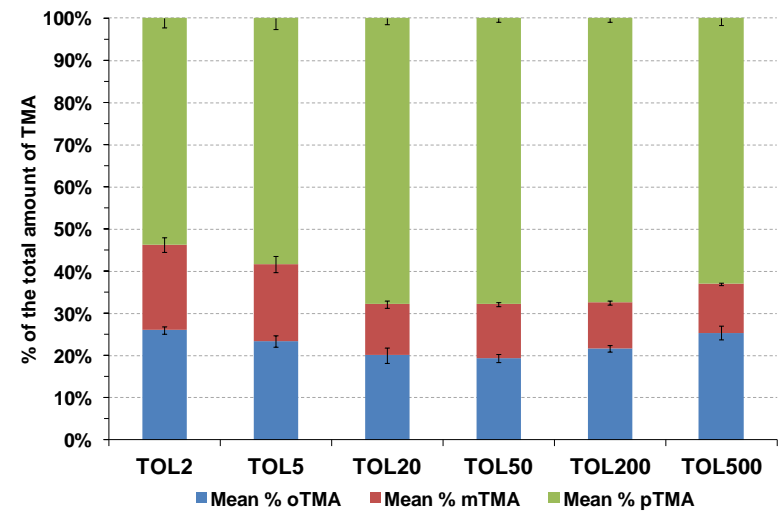

Figure 2. Proportions of mercapturic acids excreted: (A) BMA vs. TMAs, (B) ratio of the different TMA isomers 
A

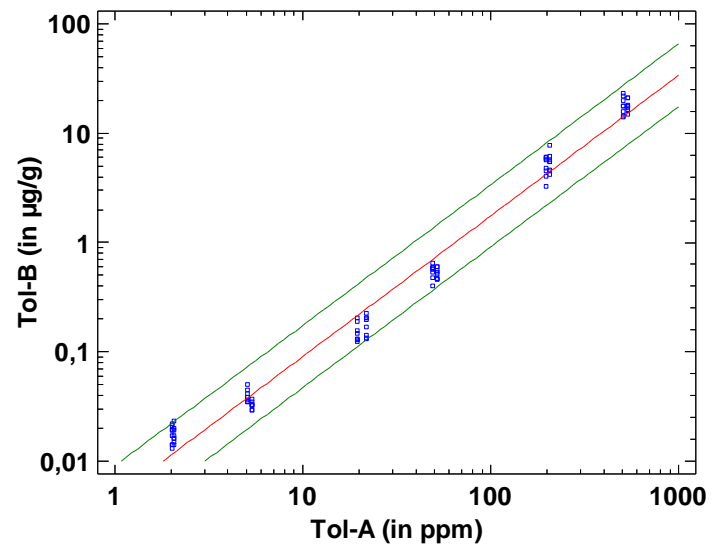

B

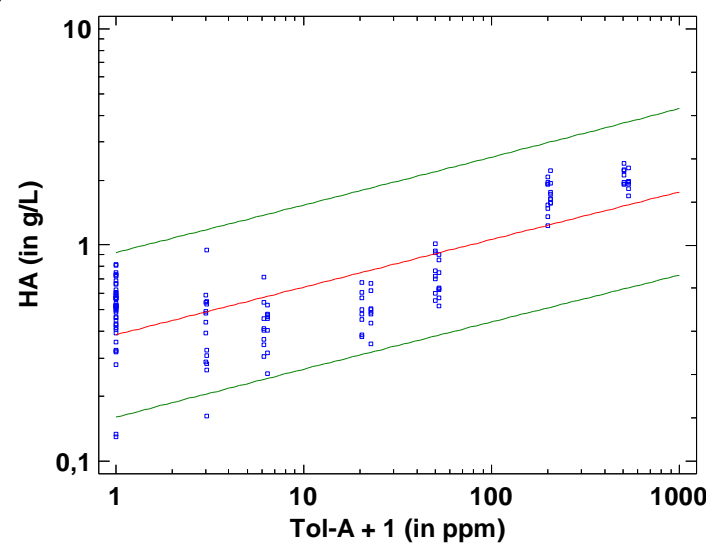

$\mathrm{D}$

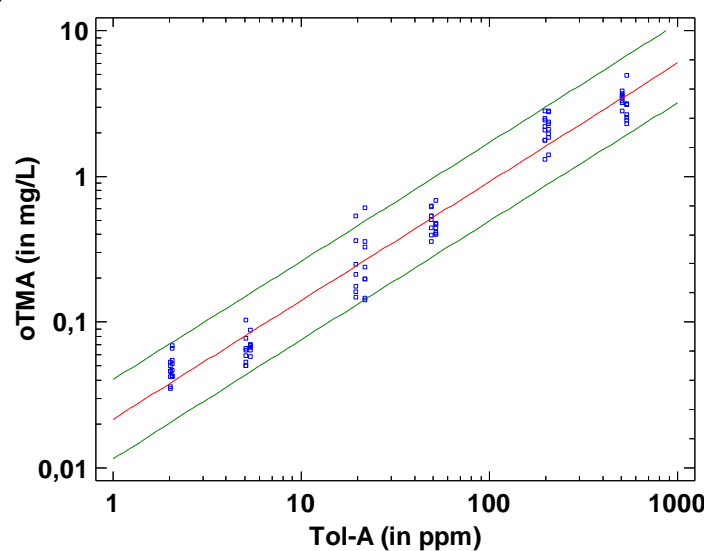

$\mathrm{F}$

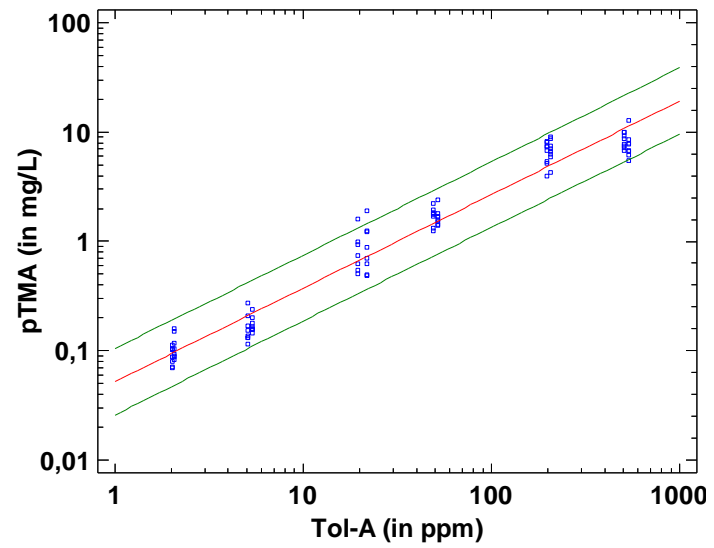

$\mathrm{C}$

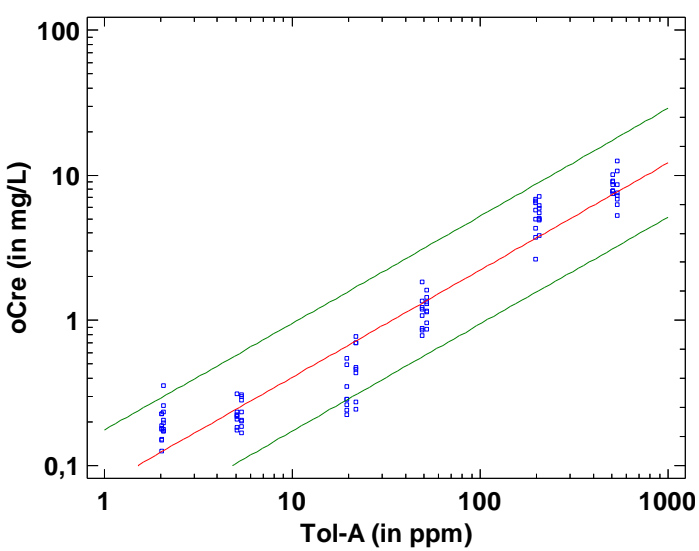

$\mathrm{E}$

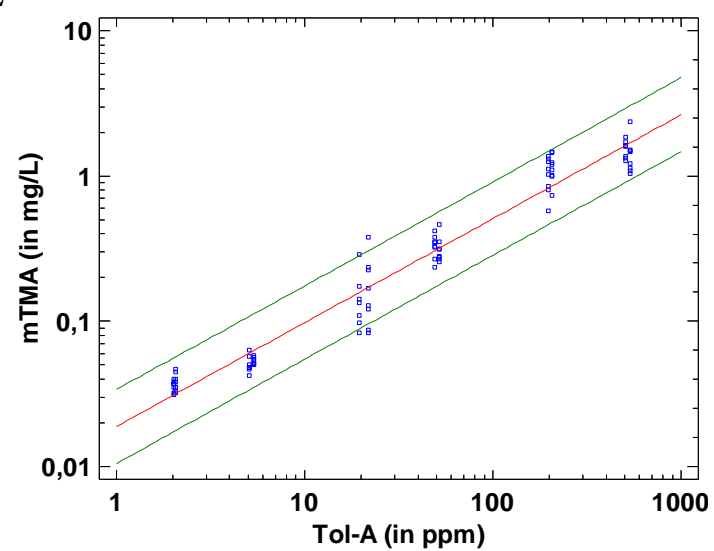

G

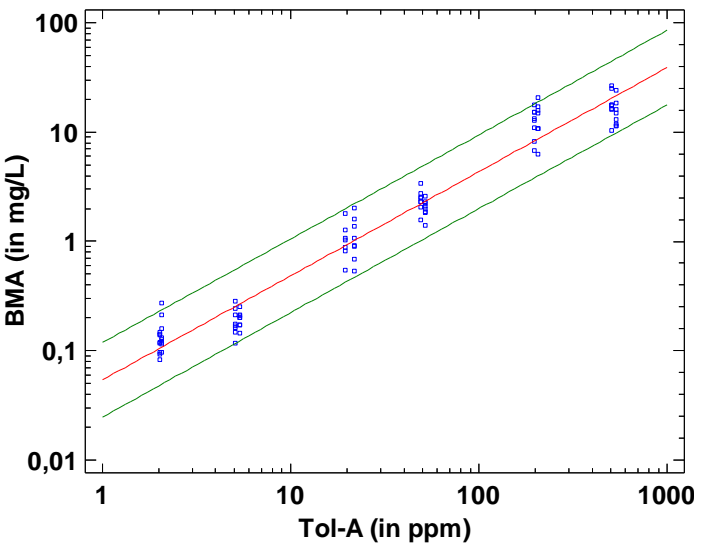

Figure 3. Relationships between the different indicators investigated and the airborne toluene concentration (log-log scale). Tol-B (A), HA (B), oCre (C), oTMA (D), mTMA (E), pTMA (F) and $\operatorname{BMA}(\mathrm{G})$ 
Table 1. Summary statistics - Mean concentrations ( \pm SD)

\begin{tabular}{|c|c|c|c|c|c|c|c|}
\hline & Day & TOL500 & TOL200 & TOL50 & TOL20 & TOL5 & TOL2 \\
\hline \multirow{2}{*}{$\begin{array}{l}\text { Tol-A } \\
\text { (ppm) }\end{array}$} & 1 & $534.0 \pm 24.3$ & $205.0 \pm 6.0$ & $51.6 \pm 0.4$ & $21.8 \pm 0.9$ & $5.39 \pm 0.41$ & $2.03 \pm 0.11$ \\
\hline & 5 & $506.3 \pm 16.3$ & $197.0 \pm 1.7$ & $49.1 \pm 1.5$ & $19.5 \pm 0.8$ & $5.11 \pm 0.09$ & $2.06 \pm 0.02$ \\
\hline \multirow{2}{*}{$\begin{array}{l}\text { Tol-B }{ }^{b} \\
(\mu g / g)\end{array}$} & 1 & $18.12 \pm 2.18$ & $5.51 \pm 1.15$ & $0.52 \pm 0.06$ & $0.18 \pm 0.04$ & $0.033 \pm 0.003$ & $0.017 \pm 0.003$ \\
\hline & 5 & $18.16 \pm 3.36$ & $5.05 \pm 1.04$ & $0.55 \pm 0.08$ & $0.15 \pm 0.03$ & $0.040 \pm 0.005$ & $0.018 \pm 0.003$ \\
\hline \multirow{3}{*}{$\begin{array}{l}\mathrm{HA}^{\mathrm{b}} \\
(\mathrm{g} / \mathrm{L})\end{array}$} & 0 & $0.58 \pm 0.13$ & $0.58 \pm 0.07$ & $0.57 \pm 0.15$ & $0.36 \pm 0.17$ & $0.50 \pm 0.17$ & $0.54 \pm 0.07$ \\
\hline & 1 & $1.95 \pm 0.18$ & $1.75 \pm 0.22$ & $0.68 \pm 0.14$ & $0.51 \pm 0.10$ & $0.42 \pm 0.09$ & $0.41 \pm 0.17$ \\
\hline & 5 & $2.11 \pm 0.19$ & $1.68 \pm 0.32$ & $0.77 \pm 0.17$ & $0.50 \pm 0.10$ & $0.44 \pm 0.13$ & $0.42 \pm 0.25$ \\
\hline \multirow{2}{*}{$\begin{array}{c}\mathrm{oCre}^{\mathrm{b}} \\
(\mathrm{mg} / \mathrm{L})\end{array}$} & 1 & $8.15 \pm 2.40$ & $5.43 \pm 1.00$ & $1.23 \pm 0.25$ & $0.51 \pm 0.20$ & $0.23 \pm 0.05$ & $0.18 \pm 0.04$ \\
\hline & 5 & $8.43 \pm 0.90$ & $5.17 \pm 1.52$ & $1.15 \pm 0.34$ & $0.34 \pm 0.12$ & $0.22 \pm 0.04$ & $0.22 \pm 0.06$ \\
\hline \multirow{2}{*}{$\begin{array}{c}\mathrm{mCre}^{\mathrm{b}} \\
(\mathrm{mg} / \mathrm{L})\end{array}$} & 1 & $0.74 \pm 0.13$ & $0.57 \pm 0.13$ & $0.14 \pm 0.04$ & $<\mathrm{LOQ}^{\mathrm{c}}$ & $<$ LOD & $<\mathrm{LOD}$ \\
\hline & 5 & $0.84 \pm 0.09$ & $0.52 \pm 0.15$ & $0.15 \pm 0.06$ & $<\mathrm{LOQ}^{\mathrm{c}}$ & $<\mathrm{LOD}$ & $<\mathrm{LOD}$ \\
\hline \multirow{2}{*}{$\begin{array}{l}\mathrm{BMA}^{\mathrm{b}} \\
(\mathrm{mg} / \mathrm{L})\end{array}$} & 1 & $15.21 \pm 4.48$ & $13.41 \pm 4.60$ & $2.04 \pm 0.36$ & $1.14 \pm 0.50$ & $0.20 \pm 0.03$ & $0.12 \pm 0.03$ \\
\hline & 5 & $18.53 \pm 5.14$ & $12.57 \pm 3.70$ & $2.44 \pm 0.53$ & $1.06 \pm 0.39$ & $0.19 \pm 0.06$ & $0.15 \pm 0.06$ \\
\hline \multirow{2}{*}{$\begin{array}{l}\mathrm{oTMA}^{\mathrm{b}} \\
(\mathrm{mg} / \mathrm{L})\end{array}$} & 1 & $3.04 \pm$ & $2.20=$ & 0.09 & $0.28 \pm 0.16$ & $0.069 \pm 0.009$ & $0.044 \pm 0.006$ \\
\hline & 5 & $3.44 \pm 0.33$ & $2.11 \pm 0.49$ & $0.50 \pm 0.10$ & $0.26 \pm 0.14$ & $0.065 \pm 0.018$ & $0.052 \pm 0.011$ \\
\hline \multirow{2}{*}{$\begin{array}{c}\mathrm{mTMA}^{\mathrm{b}} \\
(\mathrm{mg} / \mathrm{L})\end{array}$} & 1 & $1.42 \pm 0.43$ & $1.15 \pm 0.24$ & $0.32 \pm 0.07$ & $0.15 \pm 0.06$ & $0.053 \pm 0.003$ & $0.036 \pm 0.003$ \\
\hline & 5 & $1.55 \pm 0.21$ & $1.04 \pm 0.28$ & $0.33 \pm 0.06$ & $0.15 \pm 0.07$ & $0.050 \pm 0.007$ & $0.038 \pm 0.006$ \\
\hline \multirow{2}{*}{$\begin{array}{l}\mathrm{pTMA}^{\mathrm{b}} \\
(\mathrm{mg} / \mathrm{L})\end{array}$} & 1 & $7.77 \pm 2.25$ & $6.93 \pm 1.52$ & $1.69 \pm 0.33$ & $0.95 \pm 0.49$ & $0.175 \pm 0.031$ & $0.091 \pm 0.017$ \\
\hline & 5 & $7.77 \pm 8.39$ & $6.52 \pm 1.52$ & $1.73 \pm 0.32$ & $0.85 \pm 0.38$ & $0.164 \pm 0.052$ & $0.110 \pm 0.029$ \\
\hline
\end{tabular}

\footnotetext{
${ }^{a}$ three measurements per day

${ }^{\mathrm{b}} \mathrm{n}=8$ except for TOL20 on day $5(=7)$

${ }^{c}$ limit of quantification $(\mathrm{LOQ})=3 \times \mathrm{LOD}=150 \mu \mathrm{g} / \mathrm{L}$
} 
Table 2. Linear mixed-effects models for In-transformed toluene exposure indicators.

\begin{tabular}{cccccccc}
\hline Indicator & Tol-B & HA & oCre & BMA & oTMA & mTMA & pTMA \\
\hline $\mathrm{n}$ & 96 & 144 & 96 & 95 & 95 & 95 & 95 \\
\hline Fixed part & & & & & & & \\
Intercept $\alpha$ & -5.37 & -0.87 & -2.61 & -2.91 & -3.83 & -3.97 & -2.95 \\
$\quad$ (SE) & $(0.09)$ & $(0.06)$ & $(0.11)$ & $(0.10)$ & $(0.08)$ & $(0.08)$ & $(0.09)$ \\
Slope $\beta$ & 1.29 & 0.19 & 0.74 & 0.95 & 0.81 & 0.71 & 0.85 \\
$\quad$ SE) & $(0.02)$ & $(0.02)$ & $(0.03)$ & $(0.02)$ & $(0.02)$ & $(0.02)$ & $(0.02)$ \\
\hline Random part & & & & & & & \\
Between-individual SD $\psi$ & 0.27 & 0.25 & 0.34 & 0.31 & 0.26 & 0.25 & 0.30 \\
Within-individual SD $\theta$ & 0.17 & 0.4 & 0.25 & 0.22 & 0.17 & 0.14 & 0.17 \\
\hline Derived estimates & & & & & & & \\
$\rho($ rat) & 0.72 & 0.28 & 0.65 & 0.67 & 0.70 & 0.76 & 0.76 \\
$\mathrm{R}^{2}$ & 0.98 & 0.52 & 0.92 & 0.96 & 0.96 & 0.96 & 0.96 \\
\hline
\end{tabular}


Table 3. Models for In-transformed toluene exposure indicators when Tol-A $\leq 20 \mathrm{ppm}$.

\begin{tabular}{ccccccc}
\hline Indicator & Tol-B & oCre & BMA & oTMA & mTMA & pTMA \\
\hline $\mathrm{n}$ & 47 & 47 & 46 & 46 & 46 & 46 \\
\hline Intercept $\alpha(\mathrm{SE})$ & $-4.83(0.06)$ & $-1.92(0.09)$ & $-2.88(0.12)$ & $-3.70(0.11)$ & $-3.83(0.09)$ & $-3.12(0.11)$ \\
Slope $\beta(\mathrm{SE})$ & $0.97(0.03)$ & $0.31(0.05)$ & $0.91(0.06)$ & $0.72(0.05)$ & $0.61(0.05)$ & $0.93(0.05)$ \\
\hline $\mathrm{R}^{2}$ & 0.96 & 0.50 & 0.84 & 0.81 & 0.80 & 0.87 \\
\hline
\end{tabular}

